Revista de
Economild
Contemporâned

\title{
O PAPEL DO ESTADO NA POLÍTICA DE INOVAÇÃO A PARTIR DOS SEUS INSTRUMENTOS: UMA ANÁLISE DO PLANO INOVA EMPRESA
}

\author{
José Luis Gordon \\ José Eduardo Cassiolato ${ }^{b}$
}

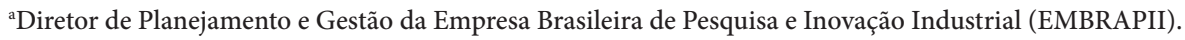
Brasília, DF, Brasil. ORCID: https://orcid.org/0000-0002-1348-1558.

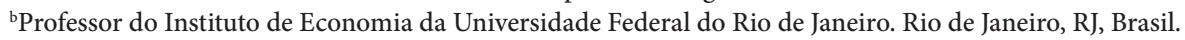
ORCID: https://orcid.org/0000-0001-8377-6012.

Artigo recebido em 16/04/2018 e aceito para publicação em 19/02/2019.

RESUMO: O trabalho aqui proposto pretende analisar o papel do Estado no Brasil no estímulo à atividade de inovação a partir dos diferentes instrumentos existentes. Para isso, será analisado o Plano Inova Empresa, que foi lançado em 2013. Nesse contexto, poderá se verificar como o governo implementou o mix de instrumentos para induzir e fomentar, no setor empresarial, a atividade inovativa de maior risco e incerteza. No trabalho, fica claro que o governo, apesar de elaborar uma política de inovação avançada, na sua implementação, acabou deixando de estruturar uma política pública que fosse capaz de induzir mudanças no comportamento das empresas. Isso se deve, em grande medida, ao baixo uso de instrumentos de redução de risco e incerteza.

PALAVRAS-CHAVE: inovação; política; Brasil.

CLASSIFICAÇÃO JEL: O38. 


\title{
THE ROLE OF THE STATE IN INNOVATION FROM ITS INSTRUMENTS: AN ANALYSIS OF THE PLANO INOVA EMPRESA
}

\begin{abstract}
The present paper aims to analyze the role of the State in Brazil in stimulating innovation activity by means of a policy instrument named Plano Inova Empresa, which was launched in 2013. The text discusses how the Brazilian government has implemented such a mix of tools to induce and foment innovation activity in the business sector, with all the risk and uncertainty that prevail in this type of endeavor. The analysis makes it is clear that, despite having designed an advanced innovation policy, the government ended up leaving behind such public policy that could have induced effective changes in the behavior of companies. This is believed to have happened because the program lacked tools for mitigating risk and uncertainty.
\end{abstract}

KEYWORDS: innovation; policy; Brazil. 


\section{INTRODUÇÃO}

A dinâmica de crescimento das economias modernas é cada vez mais impulsionada pelo processo inovativo e seus impactos ao longo de todo o Sistema Nacional de Inovação (SNI) (CASSIOLATO, 2005; FREEMAN e SOETE, 2008). Na economia do conhecimento, que caracteriza o atual modelo econômico global, as atividades de aprendizado interativo adquirem maior importância (LUNDVALL, 2007), e a atividade de inovação torna-se crescentemente complexa e sofisticada. Segundo diversos estudos (MAZZUCATO, 2013; BLOCK, 2011; ATKINSON e EZELL, 2012, 2005), historicamente, o Estado tem tido papel central na condução do processo de desenvolvimento econômico e social dos países e, em particular, governos têm utilizado seus instrumentos de política pública, a fim de diminuir riscos e incertezas inerentes ao processo inovativo (FREEMAN e SOETE, 2008).

O papel do Estado como mão visível (BLOCK, 2011) que contribui com as atividades de inovação de forma sistêmica e estruturante é o ponto de partida do presente trabalho. Assim, esse papel não se reduz a uma postura passiva, mas, sim, ativa e capaz de alterar a realidade da atividade econômica e social dos países (PEREIRA e DATHEIN, 2016). Nesse âmbito, um dos subsistemas de grande relevância do SNI é o de política pública, que tem a função de ser o vetor das estratégias de Estado para buscar o desenvolvimento econômico e social, sendo o governo o principal agente (KOELLER, 2009).

O objetivo deste artigo é verificar como o Estado brasileiro tem sido capaz de induzir e fomentar os projetos de inovação a partir de uma série de diferentes instrumentos para esse fim, como crédito, subvenção econômica, compras públicas, entre outros. A análise terá como foco o Plano Inova Empresa (PIE), que se lançou como uma das principais políticas de inovação no Brasil, no período entre 2013 e 2015. Essa foi a ação que alocou a maior soma de recursos (mais de $\mathrm{R} \$ 20$ bilhões) na década recente em estímulo a inovação a partir de diferentes instrumentos (GORDON, 2017).

A metodologia utilizada para analisar o PIE seguiu em duas etapas. Na primeira etapa, foi realizada uma revisão bibliográfica de documentos oficiais, os quais apresentam a estratégia e metas desse plano. Essa é uma forma compreender as intenções declaradas no desenho da política. As políticas públicas muitas vezes são pensadas e desenhadas pelo governo dentro de certa lógica, mas a execução pode tomar rumos divergentes daqueles apontados em documentos oficiais de formulação das políticas. Para verificar a implementação do PIE e sua coerência com aquilo que foi previsto em seu desenho, a segunda etapa da metodologia incluiu revisão bibliográfica e levantamento de dados primários junto aos órgãos envolvidos na execução do plano, a fim de subsidiar a análise das ações implantadas e não implantadas. 
Foi realizada uma revisão bibliográfica dos resultados dos editais publicados nas páginas eletrônicas do Banco Nacional do Desenvolvimento Econômico e Social (BNDES) e da Financiadora de Estudos e Projetos (FINEP). Essas informações contribuem para o entendimento dos instrumentos utilizados em cada projeto aprovado no âmbito dos editais do PIE. Em seguida, levantaram-se dados primários oriundos das instituições de fomento, que foram responsáveis pela operacionalização do PIE: BNDES e FINEP. Os dados foram solicitados por meio da Lei de Acesso à Informação (Lei no 12.527/2011) e são, portanto, informações produzidas e disponibilizadas pelas instituições. Registra-se que os dados monetários analisados foram deflacionados a partir do deflator implícito do PIB, calculado pelo Banco Central (BACEN) para o ano-base de 2015. Dessa maneira, os dados tornam-se comparáveis em termos reais. A abordagem utilizada foi baseada no conceito de número de projetos contratados e não com o conceito de desembolso anual, porque o desembolso varia muito com relação às programações financeiras das empresas e com relação à execução do projeto. Ou seja, o desembolso não necessariamente representa o comprometimento anual do governo com a política e com a temática de inovação. Portanto, o conceito de projetos contratados é mais adequado ao propósito do presente trabalho ao refletir com maior precisão os comprometimentos das instituições no fomento à inovação.

Além dessa introdução, este trabalho, na segunda seção, discutirá os diferentes instrumentos para política de inovação e suas características. $\mathrm{Na}$ terceira seção, analisará o Plano Inova Empresa, e, na última, apresentará a conclusão.

\section{INSTRUMENTOS DE POLÍTICA DE INOVAÇÃO PARA AÇÃO DO ESTADO}

As políticas públicas, inclusive as de inovação, podem ser analisadas por distintas óticas e perspectivas. No presente trabalho, procura-se entender como o Estado utiliza seus diferentes instrumentos para induzir e fomentar a atividade inovativa a partir de uma abordagem de Sistemas Nacionais de Inovação (LUNDVALL, 2007, 2005). Além de ressaltar o papel do Estado no processo inovativo, essa perspectiva enfatiza a importância de se compreender esse processo como resultado de ações de múltiplos atores, interativas, localizadas e historicamente determinadas (FREEMAN, 1989).

A atuação do Estado, com relação à inovação, se dá por meio de diferentes ações e utiliza uma gama de instrumentos de política pública. Em trabalhos clássicos, Roy Rothwell sugeriu uma classificação dos diferentes instrumentos tradicionalmente utilizados (ROTHWELL e ZEGVELD, 1981; ROTHWELL, 1983), a qual será utilizada neste texto: 
- Instrumentos do lado da oferta (supply side tools) - incluem a provisão de assistência técnica e de financiamento, além do estabelecimento de infraestrutura científica e tecnológica;

- Instrumentos do lado da demanda (demand side tools) - incluem compras governamentais (em diversos níveis de governo) e estabelecimento de contratos para o desenvolvimento de produtos, processos e serviços inovadores. (ROTHWELL, 1983, p. 204, tradução nossa)

Tanto do lado da oferta quanto do lado da demanda são variadas as possiblidades de induzir e fomentar atividades de inovação. No seu papel de elaborar políticas de inovação, o Estado pode definir e fazer interagir uma gama de instrumentos para alcançar o objetivo de aumentar a capacidade inovativa e de investimentos em inovação. A utilização desses instrumentos e como podem ser implementados torna-se crucial para a elaboração e viabilização de uma política de inovação. A decisão sobre qual ou quais instrumentos serão utilizados é uma sinalização de incentivo e indução que o Estado pretende aplicar.

Os instrumentos do lado da oferta, em sua maioria, são aqueles cujas características estão relacionadas à redução de custo e de riscos e incertezas técnicas, principalmente de atividades com alto grau de incerteza, como pesquisa e desenvolvimento (P\&D). Vários desses instrumentos propiciam o importante acesso a infraestrutura de ciência e tecnologia (C\&T), capacitações técnicas e recursos financeiros para apoio a projetos. São instrumentos que estão mais próximos ao processo de geração de novos conhecimentos e têm impacto na cadeia de valor nas áreas de pesquisa, desenvolvimento tecnológico, estágios iniciais de pesquisa, e menos na parte relacionada à difusão e inserção no mercado. O Quadro 1 apresenta as principais medidas de implementação dos instrumentos do lado da oferta. Os instrumentos mais relevantes serão analisados em seguida.

Um desses instrumentos, particularmente relevante para a redução de custo e risco técnico, é o recurso público de caráter não reembolsável, usado, por exemplo, para baratear os gastos de P\&D nas empresas e/ou para estimular a colaboração entre diferentes atores, seja entre firmas, seja entre empresas e instituições de pesquisa.

Os recursos não reembolsáveis aplicados diretamente nas empresas - subvenção econômica, como denominado no Brasil - têm grande potencial de afetar os esforços inovativos do setor produtivo, principalmente se articulado com ações discricionárias do governo (KOELLER, 2009; COSTA et al., 2013). Tais recursos são aplicados diretamente nas organizações sem a necessidade de retorno ao órgão concedente. Além de reduzir o custo do projeto, esse instrumento, potencialmente, contribui para diminuir o risco, pois, caso não obtenha sucesso, a empresa não ficará com prejuízo da 
parte que foi subsidiada. Porém, se o instrumento contribui para o arrefecimento do risco tecnológico da atividade de $\mathrm{P} \& \mathrm{D}$, de fato, ele não diminui o risco de mercado, porquanto é uma ação interna à firma e não dá conta dos problemas inerentes à estrutura de mercado e padrões de concorrência e organização industrial.

Quadro 1 - Medidas de implementação dos instrumentos do lado da oferta

\begin{tabular}{|c|c|c|c|c|}
\hline Equity support & Medidas fiscais & $\begin{array}{l}\text { Suporte para pesquisa } \\
\text { no setor público }\end{array}$ & $\begin{array}{l}\text { Suporte para } \\
\text { treinamento }\end{array}$ & $\begin{array}{c}\text { Não } \\
\text { reembolsável e } \\
\text { subsídios }\end{array}$ \\
\hline $\begin{array}{l}\text { Fundo de capital de } \\
\text { risco público }\end{array}$ & $\begin{array}{l}\text { Incentivo fiscal para } \\
\text { volume ou } \\
\text { incremento de P\&D }\end{array}$ & Fundo para ICT & $\begin{array}{l}\text { Cursos específicos } \\
\text { para as empresas }\end{array}$ & $\begin{array}{l}\text { Subvenção } \\
\text { econômica }\end{array}$ \\
\hline $\begin{array}{l}\text { Fundo de capital de } \\
\text { risco privado misto } \\
\text { ou subsidiado }\end{array}$ & $\begin{array}{l}\text { Redução de imposto } \\
\text { em folha de } \\
\text { pagamento e } \\
\text { contribuições sociais }\end{array}$ & Subsídio para colaboração & $\begin{array}{l}\text { Formação para } \\
\text { empreendedorismo }\end{array}$ & $\begin{array}{l}\text { Recursos não } \\
\text { reembolsáveis } \\
\text { para colaboração }\end{array}$ \\
\hline \multirow[t]{2}{*}{ Incentivos fiscais } & $\begin{array}{l}\text { Incentivo fiscal para } \\
\text { trabalhadores na } \\
\text { área de } P \& D\end{array}$ & $\begin{array}{l}\text { Programas estratégicos } \\
\text { para indústria }\end{array}$ & $\begin{array}{l}\text { Bolsas para estudantes } \\
\text { da indústria }\end{array}$ & $\begin{array}{l}\text { Empréstimo } \\
\text { subsidiado }\end{array}$ \\
\hline & & $\begin{array}{l}\text { Suporte para contratos de } \\
\text { pesquisa }\end{array}$ & $\begin{array}{l}\text { Suporte para } \\
\text { recrutamento de } \\
\text { cientistas }\end{array}$ & $\begin{array}{l}\text { Prêmios para } \\
\text { gastar em P\&D }\end{array}$ \\
\hline
\end{tabular}

Nota: Instituição de Ciência e Tecnologia (ICT).

Fonte: Elaboração própria com base em Edler (2007, p. 953).

Outra forma de utilizar recursos não reembolsáveis é incentivar a realização de projetos cooperativos. A política de inovação, em geral, tem estimulado a colaboração entre instituições de ciência e tecnologia (ICT) e empresas de forma que as firmas tenham acesso a conhecimentos que se somem aos internos (DODGSON, 2005; FREEMAN e SOETE, 2008; ROCHA, 2015). Nesse caso, o arrefecimento do risco tecnológico pode se dar por duas vias: a primeira, por conta do recurso não reembolsável; e a segunda, por conta da interação com ICT que pode contribuir para o desenvolvimento do conhecimento. No entanto, como na subvenção, não diminui o risco de mercado. $\mathrm{Na}$ perspectiva de sistemas de inovação aqui adotada, as atividades de colaboração adquirem importância significativa, dado que as empresas, por definição, não dispõem internamente de todos os conhecimentos e capacitações necessárias.

Alguns autores destacam que esse processo interativo é muito mais frequente e mais importante quando a relação se dá com institutos de pesquisa (CUNNUNGHAM e GOK, 2012) e com outras firmas ao longo da cadeia de produção (LUNDVALL, 2007). Por exemplo, a relação entre fornecedores e usuários estimula geração e a difusão de novos conhecimentos a fluírem ao longo de vários atores do setor produtivo (LUNDVALL, 2007). Além disso, a parceria entre empresas pode contribuir para diminuir o risco de mercado, dado que, na maioria das vezes, é feita entre usuário e produtor, gerando, dessa 
maneira, demanda para os desenvolvimentos realizados. Soma-se a isso a possibilidade de contribuir para incentivar o processo de aprendizado e para a troca de conhecimentos tácitos necessários à dinâmica inovativa (LUNDVALL, 2007).

Ainda do lado da oferta existem alguns instrumentos de caráter fiscal utilizados, por exemplo, para estimular o incremento de gastos e alocação de pessoal em atividades de $\mathrm{P} \& \mathrm{D}$. O incentivo fiscal tem como principal função diminuir os custos relacionados às atividades de $\mathrm{P} \& \mathrm{D}$. Como este reduz fundamentalmente o custo, é criticado por não estimular as empresas a se dedicarem a projetos de maior complexidade (CONNELL, 2014). De forma geral, o que se pode dizer é que as firmas não mudam seus comportamentos por causa desse instrumento (CONNELL, 2014; ZUCOLOTO, 2010) e eles se direcionam, principalmente, às atividades que seriam realizadas pelas empresas independentemente de sua existência (CASSIOLATO, 2015).

Outro instrumento do lado da oferta utilizado de forma recorrente nas políticas públicas no Brasil é o crédito. Nesse caso, a empresa necessita restituir o valor emprestado ao órgão concedente, acrescido de juros e algum tipo de correção monetária. Esse é um instrumento mais voltado para diminuir os custos das atividades de P\&D das firmas, principalmente quando há equalização de juros ou os juros são baixos, com impacto marginal na inovação propriamente dita (MELO e CARVALHO, 2013). Como as empresas precisam devolver esses recursos, por serem empréstimos, as atividades relacionadas, normalmente, são aquelas em que os riscos e as incertezas são menores e os retornos podem ser mais facilmente auferidos. Além disso, o crédito é mais adequado para o bem tangível do que para o bem intangível (MELO e CARVALHO, 2013).

Os instrumentos do lado da demanda inclinam-se a ter impacto maior no processo inovativo, dado que tendem a auxiliar na redução de risco de mercado e até, de certa forma, técnico. Diversos estudos (EDLER et al., 2013; ROTHWELL, 1983) evidenciam a importância dos instrumentos de demanda como os principais para fomentar inovação nas firmas. Em grande medida, isso ocorre, pois contribuem para a inserção do resultado do processo inovativo na economia (ROTHWELL e ZEGVELD 1981). Isso é corroborado em estudo realizado por Rothwell (1983), no qual o autor demonstra tal fato em todos os setores investigados, desde os mais complexos até os mais simples tecnologicamente. Contudo, existe um predomínio da influência das compras públicas em tecnologias mais sofisticadas. Segundo esse autor, uma forte e clara demanda governamental tem a capacidade de diminuir os efeitos de risco e incerteza. Ainda segundo o autor, no mercado futuro, quanto mais radical a inovação, mais importante torna-se esse instrumento. De acordo com Rothwell (1983), a indústria, muitas vezes, fica aprisionada (locked-in) em algumas formas de comportamento dentro das trajetórias ou regimes tecnológicos existentes, apresentando dificuldades para entrar 
em novas áreas. Em grande medida, as demandas do governo podem definir novos requisitos de funcionalidade para produtos e serviços e/ou criar mercado (EDLER, 2007), propiciando mudanças nas rotinas das corporações. As políticas do lado da demanda são, em geral, medidas públicas para gerar e/ou acelerar a difusão de inovações a partir do estímulo à demanda pública ou privada. As políticas do lado da demanda estão diretamente relacionadas aos conceitos da teoria evolucionária de interação entre produtor e usuário, de aprendizado interativo, cumulatividade, evolução e ciclo de vida de tecnologias (LEMBER et al., 2014). O Quadro 2 apresenta algumas das implementações dos instrumentos do lado da demanda.

\section{Quadro 2 - Medidas de implementação dos instrumentos do lado da demanda}

\begin{tabular}{llll}
\hline Políticas sistêmicas & \multicolumn{1}{c}{ Regulação } & Compras públicas & Suporte para demanda privada \\
\hline $\begin{array}{l}\text { Políticas para cluster } \mathrm{e} \\
\text { arranjos }\end{array}$ & $\begin{array}{l}\text { Uso de regulação para } \\
\text { impulsionar metas de inovação }\end{array}$ & $\begin{array}{l}\text { Compras públicas } \\
\text { para P\&D }\end{array}$ & $\begin{array}{l}\text { Estímulo para demanda } \\
\text { privada }\end{array}$ \\
$\begin{array}{l}\text { Políticas para a cadeia } \\
\text { produtiva }\end{array}$ & $\begin{array}{l}\text { Plataformas tecnológicas para } \\
\text { coordenar o desenvolvimento }\end{array}$ & $\begin{array}{l}\text { Compras públicas } \\
\text { de bens e serviços }\end{array}$ & Subsídios e incentivos fiscais \\
& $\begin{array}{l}\text { Compras públicas } \\
\text { na fase pré- } \\
\text { competiviva }\end{array}$ & $\begin{array}{l}\text { Articulação da demanda } \\
\text { privada }\end{array}$ \\
& $\begin{array}{l}\text { Encomendas } \\
\text { tecnológicas }\end{array}$ & $\begin{array}{l}\text { Estímulo e treinamento para } \\
\text { compras públicas catalicas }\end{array}$ \\
\hline
\end{tabular}

Fonte: Elaboração própria com base em Edler (2007, p. 953).

Dentre esses instrumentos, destacam-se as compras públicas que têm sido amplamente utilizadas pelos países mais avançados, como EUA e Suécia (MAZZUCATO, 2013; ROLFSTAM, 2012; ROTHWELL, 1983; FREEMAN e SOETE, 2008). Rothwell (1983) cita três objetivos principais para políticas de compras públicas orientadas para inovação: primeiramente a melhorar a qualidade e reduzir custo dos bens usados no setor público; em segundo a melhorar a qualidade dos bens utilizados pelo setor privado de acordo com certos objetivos sociais; e por fim a melhorar a competitividade internacional da indústria.

Pode-se destacar cinco características mais relevantes das compras públicas. Primeiramente a de geração de demandas para as empresas, criando escala e difundindo tecnologias e produtos pela economia e, assim, podendo reduzir o custo de geração de novos produtos (EDLER, 2007). Uma segunda característica é a diminuição, em função da garantia das demandas do governo, de riscos e incertezas, principalmente as de mercado, sobretudo em setores de maior complexidade de conhecimentos (ROLFSTAM, 2012). Em terceiro a possibilidade de contribuir com o fomento a tecnologias consideradas prioritárias 
pelo Estado ou áreas estratégicas. A quarta característica é a possibilidade de contribuir conjuntamente com políticas de regulação para o sucesso de atividades de inovação, como no caso de eficiência energética (EDLER, 2007); e por último estimular à produção de conteúdo local com inovação.

As compras governamentais acabam criando um ambiente favorável à inovação por meio de um potencial estímulo ao aprendizado, que facilita o aumento da capacidade inovativa do país:

It can be expected that if public procurement led to innovation and if in later stages innovation diffusion took place in other public agencies or private markets, it may have high chances to contribute to economy-wide innovation and/or market upgrading. Thus, the economy-wide innovation can in most cases be regarded as a by-product or an unplanned positive spill over from government purchasing activities. (LEMBER et al., 2014)

Vários países, como EUA, Finlândia, Suécia e China (LEMBER et al., 2014) têm procurado implementar políticas de demanda de forma sistêmica, ou seja, de maneira a ser um instrumento capaz de direcionar as demandas do Estado e organizar os processos interativos ao longo do sistema de inovação. Portanto, o instrumento de compras públicas tem um papel de contribuir com o SNI, pois gera ambiente favorável para as empresas, na medida em que tende a incentivar o desenvolvimento de novos conhecimentos, aprendizados e interação entre os agentes. Além disso, tem o papel de contribuir para a diversificação das atividades econômicas e a criação de novos mercados (LEMBER et al., 2014; MAZZUCATO, 2013; FREEMAN e SOETE, 2008).

Os muitos tipos de instrumentos (de oferta e de demanda) têm impactos variados nas distintas atividades e nos tipos de inovação, tendo em vista o grau de incerteza e risco inerente ao processo inovativo. ${ }^{1}$ Teoricamente, cada um dos instrumentos deveria ser utilizado, individual ou coletivamente, de forma a propiciar melhor influência do Estado nas atividades de inovação. Os instrumentos têm potencial de utilização em uma lógica interativa, intensificando os efeitos que cada um apresenta.

O Quadro 3 apresenta uma proposta de associação entre tipos de instrumentos, tendo em vista as estratégias do Estado para indução e fomento de geração e difusão

\footnotetext{
1 O caráter aparentemente aleatório, acidental e arbitrário do processo inovativo advém da extrema complexidade das interfaces entre o progresso científico, a tecnologia e as mudanças de mercado (FREEMAN e SOETE, 2008, p. 351).
} 
de tecnologias e diferentes etapas do processo inovativo, tipos de inovação e graus de incerteza e risco ${ }^{2}$ associados à inovação.

Quadro 3 - Relação entre inovação, incerteza, risco e instrumentos de política

\begin{tabular}{|c|c|c|c|}
\hline Tipo de Inovação & Incerteza & Risco & Instrumento \\
\hline Pesquisa básica e invenção & $\begin{array}{l}\text { Incerteza } \\
\text { verdadeira }\end{array}$ & Incalculável & $\begin{array}{l}\text { - não reembolsável } \\
\text { - encomenda tecnológica } \\
\text { - capital de risco }\end{array}$ \\
\hline $\begin{array}{l}\text { Inovações radicais de produto e } \\
\text { processo desenvolvidas fora da } \\
\text { empresa }\end{array}$ & $\begin{array}{l}\text { Altíssimo grau de } \\
\text { incerteza }\end{array}$ & Altíssimo & $\begin{array}{l}\text { - participação/subvenção } \\
\text { - compras públicas } \\
\text { - encomenda tecnológica } \\
\text { - capital de risco }\end{array}$ \\
\hline $\begin{array}{l}\text { Inovações de produto e } \\
\text { inovações de processo na própria } \\
\text { empresa }\end{array}$ & $\begin{array}{l}\text { Alto grau de } \\
\text { incerteza }\end{array}$ & Alto & $\begin{array}{l}\text { - participação/ subvenção } \\
\text { - compras públicas } \\
\text { - recursos não reembolsáveis } \\
\text { para interação ict/empresa } \\
\text { - capital de risco }\end{array}$ \\
\hline $\begin{array}{l}\text { Nova geração de produtos } \\
\text { conhecidos }\end{array}$ & $\begin{array}{l}\text { Incerteza } \\
\text { moderada }\end{array}$ & Moderado & $\begin{array}{l}\text { - crédito equalizado } \\
\text { - recursos não reembolsáveis } \\
\text { para interação ict/empresa }\end{array}$ \\
\hline $\begin{array}{l}\text { Inovação sob licença; imitação e } \\
\text { diferenciação de produto; } \\
\text { melhoramentos e adaptações em } \\
\text { produtos e processos }\end{array}$ & Baixa incerteza & Baixo & $\begin{array}{l}\text { - crédito (em alguns casos } \\
\text { com equalização) } \\
\text { - incentivo fiscal }\end{array}$ \\
\hline $\begin{array}{l}\text { Diferenciação de produto; } \\
\text { inovação de produto conhecido; } \\
\text { adoção tardia de inovação de } \\
\text { processo estabelecido na própria } \\
\text { firma; melhoramentos técnicos } \\
\text { secundários }\end{array}$ & $\begin{array}{l}\text { Incerteza muito } \\
\text { baixa }\end{array}$ & Muito baixo & $\begin{array}{l}\text { - crédito } \\
\text { - incentivo fiscal }\end{array}$ \\
\hline
\end{tabular}

Fonte: Elaboração própria com base em Melo e Carvalho (2013) e Freeman e Soete (2008).

Conforme o Quadro 3, existe um conjunto de instrumentos que contribuem mais para a redução do risco e incerteza da atividade de inovação que outros. ${ }^{3}$ Devido a essas características do processo de inovação, uma parte pequena das empresas vai se financiar pelo mercado de capitais ou por mecanismos como crédito. De forma geral,

2 De forma geral, pode-se dizer que a incerteza difere dos riscos, pois esse último pode ser calculado (FREEMAN e SOETE, 2008, p. 416).

3 A intervenção do Estado na promoção de mudanças socializa os riscos, contribuindo para reforçar a interdependência entre empresas e os demais agentes inovadores. Isso é importante porque transfere da firma a individual parte dos custos da sua decisão, o que permite direcionar novos investimentos (PEREIRA e DATHEIN, 2016, p. 37). 
as corporações vão se autofinanciar ou buscar alguma forma de apoio de governo que contribua para a redução dos riscos (FREEMAN e SOETE, 2008). Idealmente, o Estado deveria ser capaz de apresentar um leque de instrumentos apropriados a induzir e fomentar a atividade inovativa segundo os graus de risco e incerteza (PEREIRA e DATHEIN, 2016). A escolha de qual instrumento ou o mix de instrumentos a ser utilizado deveria fazer parte da ação estratégica do poder público. Além disso, esse leque de instrumentos tende a ser ajustado e reformulado na medida em que as tecnologias evoluem para manter o setor produtivo continuamente inovando (CASSIOLATO, 2015).

\section{PLANO INOVA EMPRESA}

Na década de 1990, o Brasil passou por mudanças importantes na condução de seu processo de desenvolvimento e de crescimento econômico e, nesse período, a política industrial foi posta de lado pelo governo federal (CASSIOLATO, 2016).

Somente com a mudança do governo no ano de 2003 é que as políticas de inovação e industrial passaram a ganhar novos contornos e alguma relevância para a dinâmica de crescimento econômico do país (GADELHA, 2016; CASSIOLATO, 2016). A partir desse momento, o Estado procurou criar mecanismos para contribuir com o processo de inovação, buscando estruturar políticas explícitas de inovação (COSTA et al., 2013; GADELHA, 2016). No início de 2004, o governo federal lançou a Política Industrial, Tecnológica e de Comércio Exterior (PITCE). No começo de 2008, foi lançada a Política de Desenvolvimento Produtivo (PDP) para o período de 2008 a 2010.

Dando continuidade a esse processo, em 2011, o governo brasileiro empenhou-se em criar políticas no intuito de fortalecer a capacidade industrial e inovativa do país (ARBIX e DE NEGRI, 2015; FERRAZ et al., 2015). Uma dessas foi o Plano Brasil Maior (PBM), que apresentou uma série de ações para estimular o setor privado nacional (GADELHA, 2016); outra ação foi a Estratégia Nacional de Ciência e Tecnologia (ENCTI 2011-2015), que se tornou a base estratégica da política de inovação do país. Além disso, o governo lançou, em 2013, no âmbito da articulação entre PBM e ENCTI, o Plano Inova Empresa (PIE), administrado pela Financiadora de Estudos e Projetos (Finep) e pelo Banco Nacional de Desenvolvimento Econômico e Social (BNDES), em parceria com alguns ministérios setoriais, de forma a fomentar projetos de inovação em áreas estratégicas (CORNER, 2016; AMARAL et al., 2014; ARBIX e DE NEGRI, 2015; FERRAZ et al., 2015; PEREIRA et al., 2015). 


\subsection{A ESTRUTURA DO PLANO INOVA EMPRESA}

O PIE tinha por objetivo central investir em inovação para elevar a produtividade e a competitividade da economia brasileira (BRASIL, 2013). No lançamento da política, em 2013, alguns pontos essenciais para sua concepção foram (BRASIL, 2013) os seguintes: fomento a planos de inovação empresariais; descentralização do crédito e da subvenção econômica para médias e pequenas empresas; e, por fim, novo modelo de fomento à inovação. Este último tinha as seguintes ações: articulação de programas de diversas instituições públicas; uso coordenado dos instrumentos: crédito, subvenção, renda variável e não reembolsável; redução de prazos e simplificação administrativa.

De certa forma, o PIE apresentou avanços em relação a políticas como PITCE (2004-2007) e PDP (2008-2010) (GORDON, 2017; ARBIX e DE NEGRI, 2015). Por exemplo, várias instituições participaram coordenadamente do programa de forma ativa, principalmente o BNDES e a Finep, mas também ministérios setoriais se envolveram na sua formulação, como o Ministério da Saúde e o Ministério da Defesa, entre outros. Além disso, procurou-se articular os diferentes instrumentos existentes para fomentar atividades de inovação nas empresas, e essa integração ocorreu não somente ao se disponibilizar uma série de instrumentos, mas na tentativa de aplicá-los conjuntamente, de forma organizada, para intensificar a atividade de inovação (AMARAL et al., 2016; MAZZUCATO e PENNA, 2016). Este talvez tenha sido o maior avanço do programa, pois a coordenação do uso dos instrumentos requer que o setor público esteja alinhado em torno de uma estratégia nacional. Além disso, o PIE definiu focos setoriais: Aeroespacial e Defesa, Agroindústria, Energia, Petróleo e Gás, Saúde, Sustentabilidade, Telecomunicação, Sucroenergético e Sucroquímico.

O programa utilizou diferentes instrumentos, apresentados na Tabela 1. O propósito do programa era que as empresas utilizassem uma combinação de tais instrumentos. As taxas de juros para o crédito praticadas no programa eram bastante atraentes $(7 \%$ ao ano para empresas de maior porte), considerando o nível elevado de juros cobrados no mercado privado nacional e a dificuldade de acessar linhas para inovação fora do setor público no país. ${ }^{4}$ Havia, ainda, um estímulo extra para micro, pequenas e médias empresas (taxas de juro em 6,5\% ao ano). Como visto na Tabela 1, a maioria dos recursos (mais de 60\%) seria alocada em crédito subvencionado.

4 A taxa de juros Selic em 25/01/2014 era de 10,5\% a.a. (BACEN). 
Tabela 1 - Instrumentos de política utilizados no PIE

\begin{tabular}{|c|c|c|c|c|}
\hline Instrumento & $\begin{array}{l}\text { Valor em } \\
\text { R\$ bilhões }\end{array}$ & $\begin{array}{l}\% \text { do } \\
\text { total }\end{array}$ & Impacto do instrumento & Forma do instrumento \\
\hline Crédito & 20,9 & 63,5 & Redução de custo & Lado da oferta \\
\hline Subvenção econômica & 1,2 & 3,6 & Redução de risco e custo & Lado da oferta \\
\hline $\begin{array}{l}\text { Não reembolsável para cooperação } \\
\text { empresa e ICT }\end{array}$ & 4,2 & 12,8 & Redução de risco e custo & Lado da oferta \\
\hline Renda variável & 2,2 & 6,7 & Redução de custo e risco & Lado da oferta \\
\hline $\begin{array}{l}\text { ANP (obrigatoriedade de gasto em } \\
\text { P\&D) })^{5}\end{array}$ & 2,5 & 7,6 & Obrigatoriedade & Lado da oferta \\
\hline $\begin{array}{l}\text { ANEEL (obrigatoriedade de gasto em } \\
\text { P\&D) }\end{array}$ & 0,6 & 1,8 & Obrigatoriedade & Lado da oferta \\
\hline Sebrae (não reembolsável) & 1,3 & 4 & Redução de risco e custo & Lado da oferta \\
\hline Total & 32,9 & 100 & & \\
\hline
\end{tabular}

Notas: ANP - Agência Nacional do Petróleo; ANEEL - Agência Nacional de Energia Elétrica; Sebrae - Serviço Brasileiro de Apoio às Micro e Pequenas Empresas.

Fonte: Brasil (2013).

\subsection{A IMPLEMENTAÇÃO DO PLANO INOVA EMPRESA}

Essa parte do trabalho analisa a implementação do PIE para que se possa verificar o que, de fato, foi realizado nas ações da política. Serão analisados os resultados de alguns editais lançados e dados oficiais dos projetos contratados.

\subsubsection{OS EDITAIS LANÇADOS}

Uma das características do PIE foi a publicação de editais conjuntos entre diferentes instituições, o que realça maior coordenação da política e possibilita redução de custos e burocracia para as empresas. Isso se deve ao fato de as firmas passarem a ter uma porta de entrada comum entre as instituições, permitindo maior competição entre as concorrentes (FERRAZ et al., 2015; PEREIRA et al., 2015). Quase todos os editais apresentavam um conjunto variado de instrumentos disponibilizados que poderiam ser demandados pelas firmas em seus projetos de P\&D (GORDON, 2017). Alguns exemplos podem ser analisados.

5 Os recursos da ANP (Lei n 9.478/1997) e da ANEEL (Lei nº 9.991/2000) são relativos ao modelo de regulação que exige das empresas obrigatoriedade de gasto em P\&D. 
O edital do Inova Saúde Fármacos ${ }^{6}$ (FINEP, 2013b) foi elaborado em conjunto pela FINEP, o então Ministério da Ciência, Tecnologia e Inovação (MCTI), o Conselho Nacional de Desenvolvimento Científico e Tecnológico (CNPq) e o Ministério da Saúde (MS). Além dos instrumentos já disponibilizados pela política, foram acrescentados ao menu de opções os seguintes instrumentos do MS:

- Encomenda - suporte financeiro não reembolsável a projetos executados por ICT e produtores públicos para desenvolvimento de tecnologias estratégicas ao SUS;

- Aquisição Estratégica - uso do poder de compra e garantia de demanda futura para produtos e bens em conformidade com o estabelecido pela Portaria $n^{\circ}$ 837, de 18 de abril de 2008; e

- PROCIS - Programa para o Desenvolvimento do Complexo Industrial da Saúde, que objetivava fortalecer os produtores públicos e a infraestrutura de produção e inovação em saúde do setor público.

Os instrumentos - na sua maioria, do lado da demanda - poderiam totalizar R\$ 200 milhões (FINEP, 2013b).

O edital Inova Saúde Fármacos teve como resultado final: 21 projetos aprovados, todos receberam crédito da Finep, 13 auferiram subvenção econômica, quatro obtiveram recursos do MS em função de Parceria para o Desenvolvimento Produtivo (PDP) e três conseguiram bolsas do CNPq (FINEP, 2013b). Duas empresas receberam conjuntamente crédito, subvenção e recursos do MS. Projetos nas áreas de biofármacos, farmoquímicos e medicamentos são de alto risco, portanto, a utilização de variados instrumentos é uma forma de levar as empresas a se engajarem mais em atividades de geração de novos conhecimentos. Nesse edital, notou-se relativa integração entre os diversos instrumentos, ainda que tenham sido aprovados apenas quatro casos relacionados às PDP, que direcionam a agenda de encomendas do MS.

O edital Inova Saúde Equipamentos, além dos instrumentos tradicionais, também previa o uso de encomenda tecnológica, no âmbito da PDP, e mais aporte de R\$50 milhões, oriundos do MS (BNDES, 2013b). No edital, foram aprovados 45 projetos, contemplados da seguinte maneira: 21 receberiam créditos da Finep, 21 receberiam créditos do BNDES, dez receberiam recursos não reembolsáveis (sendo que quatro receberiam só essa modalidade) e dois receberiam aporte de recursos do MS (BNDES, 2013b). É digno de nota o fato de apenas seis projetos terem aprovado recursos de crédito e não reembolsável e mais dois terem aprovado créditos e recursos do MS

6 O Sistema único de Saúde (SUS) tem grande capacidade de demanda por produtos tanto na área de equipamentos quanto em fármacos (GADELHA, 2012). 
conjuntamente. Tal constatação demonstra que a principal marca da política, que é o mix de instrumentos, não foi implementada.

No caso do Inova Petro, a participação da Petrobras se deu apenas na elaboração do edital. Portanto, não existiu nenhum mecanismo de encomenda ou compras públicas por parte da empresa. Esse fato diminuiu a contribuição que a instituição poderia dar a partir de seu poder de demanda para alavancar um número maior de projetos ao longo da cadeia e com maior complexidade.

No edital do Inova Energia de 2013, foram aprovados 56 projetos de empresas líderes (BNDES, 2013a), os quais se transformaram num total de 106 planos de negócios ${ }^{7}$ que, em alguns casos, envolveram parcerias com outras firmas ou instituições de pesquisa. Apenas 38 planos de negócios foram contemplados com mais de um instrumento, ou seja, a ideia central de integrar diferentes instrumentos não foi aplicada.

No caso do Inova Aerodefesa, a Agência Espacial Brasileira (AEB) e o Ministério da Defesa participaram da formulação da política, e aqui mais uma vez diferentes atores interagiram. Sobre os instrumentos dessas instituições, além dos tradicionais já disponibilizados, o edital de 2013 apresentava como alternativa:

Aquisição estratégica - possibilidade de garantir demanda futura para os equipamentos e serviços desenvolvidos, de acordo com a disponibilidade orçamentária dos órgãos e atendimento de requisitos aplicáveis, além de condições e normas determinadas pelo MD e pela AEB. O eventual apoio por parte do MD deverá ser inteiramente compatível com as prescrições da Lei nº 8.666/1993, da Lei $\mathrm{n}^{\circ} 12.598$ de 22.03.2012, e do decreto $\mathrm{n}^{\circ} 7.970$ de 28.03.2013, além de outras normas aplicáveis à espécie. (FINEP, 2013a, p. 6)

Existia, portanto, a possibilidade de se utilizar o instrumento de compras públicas. No entanto, em um setor que depende fortemente das demandas do poder público (MOWERY, 2010), o fato de não haver a certeza, mas apenas a intenção, da implementação desse instrumento pode ter esvaziado as aspirações das empresas. $\mathrm{O}$ programa teve 12 planos de negócio aprovados que receberiam recursos de diferentes instrumentos. Os outros 80 planos de negócio aprovados iriam receber fundamentalmente crédito.

Dos nove editais lançados entre 2013 e 2014 e aqui analisados, em oito não houve, de forma predominante, a integração de instrumentos, e os projetos foram contemplados

\footnotetext{
7 As empresas líderes podem ter mais de um projeto aprovado para cada plano de negócio com diferentes parceiros ou sozinhas. Foram 56 planos de negócio de empresas líderes aprovadas com 106 projetos.
} 
majoritariamente apenas com recursos reembolsáveis (GORDON, 2017). A partir da análise do resultado dos editais, conclui-se que boa parte dos instrumentos utilizados é do lado da oferta e com grande predominância do crédito. Empresas não precisam de um programa como esse para apenas demandar crédito, pois essa ação já é rotineira nas instituições de fomento, como BNDES e FINEP. Assim, o uso do mix de instrumentos não foi praticamente implementado e aqueles de redução de risco e incerteza foram muito pouco disponibilizados.

\subsubsection{ALOCAÇÃO DE INSTRUMENTOS EM PROJETOS APROVADOS NO PIE}

A seguir, serão apresentados alguns dados sobre a contratação dos projetos com os instrumentos de crédito, subvenção econômica e FUNTEC do BNDES. Dessa forma, será possível observar como, de fato, ocorreu a disposição dos recursos para o PIE.

Tabela 2 - Valor por instrumento em projetos contratados em cada ano (em R\$ constantes de dez/2015*)

\begin{tabular}{|c|c|c|c|c|c|}
\hline Instrumento & 2012 & 2013 & 2014 & 2015 & Total \\
\hline FINEP (Crédito) & 284.702 .717 & 7.464.227.243 & 9.285 .114 .125 & 319.923 .834 & 17.353.967.919 \\
\hline BNDES (Crédito) & & 1.719 .598 .419 & 1.225 .893 .454 & 300.798 .515 & 3.246 .290 .388 \\
\hline Total crédito & 284.702 .717 & 9.183 .825 .662 & 10.511 .007 .580 & 620.722 .349 & 20.600.258.307 \\
\hline Subvenção Econômica (FINEP) & & 110.059 .790 & 241.814 .538 & 106.023 .091 & 457.897 .420 \\
\hline FUNTEC (BNDES) & & 4.230 .753 & 23.602 .898 & 70.661 .460 & 98.495 .112 \\
\hline Total Geral & 284.702 .717 & 9.298 .116 .205 & 10.776 .425 .016 & 797.406 .900 & 21.156 .650 .838 \\
\hline
\end{tabular}

Nota: (*) Deflator implícito do PIB/BACEN.

Fonte: Elaboração própria a partir de dados do BNDES e da FINEP (Lei de Acesso à Informação).

A Tabela 2 mostra a evolução dos recursos do PIE em projetos contratados em cada ano, por diferentes instrumentos. De 2012 até 2015, foram contratados no total R \$20,6 bilhões em projetos com crédito, o que representa uma quantidade substancial e demonstra a procura do setor produtivo pelo Inova Empresa. ${ }^{8} \mathrm{O}$ crédito com equalização de juros para as empresas desenvolverem projetos de $\mathrm{P} \& \mathrm{D}$, mesmo com as

\footnotetext{
8 Trata-se, sem dúvida, de um montante expressivo e inédito alocado para projetos com conteúdo inovador no país, e todo o processo mereceria um acompanhamento cuidadoso para avaliar os resultados diretos e indiretos do financiamento, e ponderar os ganhos efetivos que validam (ou não) as condições especiais e o ônus assumido pelo Tesouro (CORNER et al., 2016, p.8).
} 
características apresentadas na seção 2, obteve grande aderência. Tal fato realça a importância das ações do governo para estimular a inovação. ${ }^{9}$ Chama atenção o fato de que, nos anos 2013 e 2014, houve grande contratação de projetos com mais de R\$ 9,1 bilhões e R\$ 10,5 bilhões com crédito, ${ }^{10}$ respectivamente.

Entretanto, o ano de 2015 apresentou grande queda. Para a inovação ser o motor do crescimento econômico, é necessário que as ações para estimular o esforço inovativo durem por longos períodos de tempo (LAZONICK, 2011). A interrupção de ações, como no ano de 2015, gera um ambiente desfavorável ao investimento, pois proporciona incertezas quanto às medidas de apoio.

Cabe destacar que o programa previa $\mathrm{R} \$ 1,4$ bilhão ${ }^{11}$ em subvenção, mas contratou apenas R\$ 496 milhões, ou seja, somente um terço do valor anunciado. Provavelmente, isso se deve mais à falta de recursos do governo para esse instrumento do que à falta de demandas empresariais.

Analisando a Tabela 3, verifica-se o percentual de recursos de subvenção econômica no Inova Empresa.

Tabela 3 - Percentual de subvenção econômica sobre o crédito em projetos contratados no Inova Empresa (\%)

\begin{tabular}{lcccc}
\hline & $\mathbf{2 0 1 3}$ & $\mathbf{2 0 1 4}$ & $\mathbf{2 0 1 5 \mathbf { 1 } ^ { 1 2 }}$ & Total \\
\hline Percentual de subvenção/crédito & 1,2 & 2,3 & 17,1 & 2,3 \\
\hline
\end{tabular}

Fonte: Elaboração própria com base em dados do BNDES e da FINEP (Lei de Acesso à Informação).

Diante dos dados, nota-se que o valor total de subvenção sobre o crédito em projetos contratados entre 2013 e 2015 é de 2,3\%, bem abaixo dos 5,7\% previstos. Isso é um ponto negativo da ação do governo federal, que não alocou os recursos previstos para esse instrumento, mesmo resultado encontrado por Corner et al. (2016). ${ }^{13} \mathrm{Tal}$ fato demonstra que o Estado brasileiro não destacou subvenção como um dos componentes fundamentais para incentivar atividades de P\&D.

\footnotetext{
9 A procura por financiamento com crédito demonstra que existe uma demanda reprimida por parte das empresas por projetos de inovação.

${ }^{10}$ Esse valor está corrigido pelo defletor implícito do PIB para o ano de 2015. No ano de lançamento do programa (2013), a previsão era de R\$20,9 bilhões.

11 Esse valor está corrigido pelo defletor implícito do PIB para o ano de 2015. No ano de lançamento do programa (2013), a previsão era de R\$1,2 bilhão.

12 Em 2015 o percentual foi alto em função da queda em crédito.

13 Ainda que seja muito cedo para avaliar o Inova Empresa, é possível afirmar que o desequilíbrio entre os recursos alocados sob a forma de crédito e sob a forma de subvenção revela que o Inova Empresa não se distingue das linhas de financiamento que vinham sendo disponibilizadas no âmbito do Plano de Sustentação do Investimento (PSI), (CORNER et al., 2016, p. 11).
} 
A Tabela 4 mostra a contratação por setor com alguns instrumentos.

Tabela 4 - Projetos contratados BNDES e FINEP do Inova Empresa por grande área (em R\$ constantes de dez/2015* - R\$ 1.000)

\begin{tabular}{|c|c|c|c|c|c|c|}
\hline & \multicolumn{2}{|c|}{$\begin{array}{c}\text { Crédito } \\
(\text { FINEP + BNDES })\end{array}$} & \multirow{2}{*}{$\begin{array}{c}\begin{array}{r}\text { Subvenção } \\
\text { econômica }\end{array} \\
\text { Total }\end{array}$} & \multirow{2}{*}{$\begin{array}{c}\text { FUNTEC/ } \\
\text { BNDES } \\
\text { Total }\end{array}$} & \multirow[t]{2}{*}{ Total Geral } & \multirow[t]{2}{*}{$\begin{array}{c}\% \text { do total } \\
\text { geral }\end{array}$} \\
\hline Inova Empresa & Total & $\begin{array}{l}\text { Valor médio } \\
\text { dos projetos }\end{array}$ & & & & \\
\hline $\begin{array}{l}\text { Agropecuária e } \\
\text { agroindústria }\end{array}$ & 1.864 .463 & 31.074 & 20.981 & 9.079 & 1.894 .523 & 9,0 \\
\hline $\begin{array}{l}\text { Complexo aeroespacial e } \\
\text { defesa }\end{array}$ & 556.497 & 61.833 & 124.033 & 52.800 & 733.330 & 3,5 \\
\hline Complexo da saúde & 2.659 .807 & 75.994 & 100.838 & & 2.760 .645 & 13,0 \\
\hline Energia (incluindo PAISS) & 5.938 .899 & 98.982 & 115.317 & 36.616 & 6.090 .832 & 28,8 \\
\hline $\begin{array}{l}\text { Micro e pequenas } \\
\text { empresas }\end{array}$ & 1.212 .682 & 71.334 & & & 1.212 .682 & 5,7 \\
\hline $\begin{array}{l}\mathrm{P} \& \mathrm{D} \text {, inovação e } \\
\text { engenharia de produtos e } \\
\text { processos }\end{array}$ & 5.609 .749 & 43.486 & & & 5.609 .749 & 26,5 \\
\hline Petróleo e gás & 1.061 .698 & 48.259 & 5.426 & & 1.067 .124 & 5,0 \\
\hline $\begin{array}{l}\text { Tecnologia da informação } \\
\text { e comunicação }\end{array}$ & 1.521 .698 & 46.112 & 87.036 & & 1.608 .734 & 7,6 \\
\hline Inova Sustentabilidade & 174.765 & 21.846 & 4.267 & & 179.032 & 0,8 \\
\hline Total geral & 20.600 .258 & 55.229 & 457.897 & 98.495 & 21.156 .650 & 100,0 \\
\hline
\end{tabular}

Nota: (*) Deflator implícito do PIB/BACEN.

Fonte: Elaboração própria a partir de dados do BNDES e da FINEP (Lei de Acesso à Informação).

Pela Tabela 4, o setor que mais efetivou contratação de projetos foi o de energia, com R \$ 6 bilhões. Esse setor, no lançamento do plano, era aquele com maior previsão de destino de recursos. Foram contratados 60 projetos nos diversos editais ligados à área de energia, totalizando um valor médio por projeto de $\mathrm{R} \$ 98$ milhões com crédito (GORDON, 2017).

O segundo em contratação foi na área de $\mathrm{P} \& \mathrm{D}$, inovação e engenharia de produtos e processos, com R\$ 5,6 bilhões. Os projetos são em áreas variadas, como engenharia, logística, química, serviços, têxtil, transporte, entre outros. No lançamento da política, esse segmento teria aporte de R\$ 1 bilhão, fundamentalmente em duas ações (BRASIL, 2013):

- PSI-Inovação: apoio a investimentos em P\&D, ao desenvolvimento de inovações em produto, processo e marketing; e

- PSI-Engenharia: apoio a projetos de engenharia no setor automotivo, de bens de capital, defesa, aeronáutico, aeroespacial, nuclear, petróleo e gás e petroquímico. 
As ações citadas estão mais voltadas para engenharia e apoio a atividades ligadas à inovação que não envolvem tanto risco. Tal fato seria um reflexo da estrutura produtiva nacional, que tende a fazer inovações mais em projetos de engenharia e com menor complexidade tecnológica. A estrutura produtiva brasileira é predominantemente formada por setores de baixo conteúdo tecnológico e baixa capacidade de exportação em setores de maior intensidade tecnológica (GRAMKOW e GORDON, 2015).

Vale destacar o fato de, no crédito, terem sido contratados 373 projetos com valor médio de R 55 milhões (GORDON, 2017). Projetos médios com esse valor tendem a ser considerados altos para atividades de inovação, cuja essência é o conhecimento (FREEMAN e SOETE, 2008), assim, nesses, deve estar envolvida grande quantidade de recursos para infraestrutura e capital. Dessa maneira, seguem as características de inovação da indústria nacional cuja estratégia se centra mais na aquisição de máquinas e menos em desenvolvimento de novos produtos (ARBIX e DE NEGRI, 2015).

Nos recursos de subvenção econômica, o setor que obteve maior percentual do valor total em contratos assinados foi o complexo aeroespacial e defesa $(27,1 \%)$, que é um setor intensivo em tecnologia. No FUNTEC/BNDES, a área foi também contemplada com a maior soma de recursos não reembolsáveis para interação ICTempresa. No segmento aeroespacial e defesa, os projetos envolvem muito conhecimento, assim é essencial o uso de instrumentos de redução de risco. O que chama atenção é o baixo montante de contratação de projetos para a área, o que elevou o percentual de subvenção e FUNTEC. Algumas hipóteses podem ser levantadas para explicar o baixo volume de projetos contratados nessa área: primeiro, por ser um setor altamente complexo e com risco, o modelo de crédito tende a não ser o mais atraente isoladamente; segundo, o principal componente de redução de risco nessa área são as compras e encomendas do governo (MOWERY, 2010) e, como ressaltado anteriormente, não havia garantia da demanda do Ministério da Defesa.

\subsubsection{DISCUSSÃO SOBRE O USO DOS INSTRUMENTOS NO PLANO INOVA EMPRESA}

Diante do que foi analisado neste trabalho, pode-se dizer, de forma geral, sobre o Plano Inova Empresa, que, apesar de representar grande avanço na concepção de uma política de inovação, não cumpriu sua missão de gerar ambiente favorável ao desenvolvimento inovativo. Nota-se que o uso de instrumentos do lado da oferta e da demanda para diminuir risco e incertezas foi extremamente limitado. A implementação ocorreu focada em disponibilizar grandes volumes de crédito, o que, pelas características do instrumento, já destacadas na seção 2, não contribui por si só para que as firmas mudem suas rotinas e estratégias. Dessa maneira, dificulta-se o estabelecimento de um 
processo no qual o poder público possa estimular e induzir a geração e difusão endógena de novos conhecimentos. Além disso, esse instrumento tampouco estimula a troca de conhecimentos, o que é um limitador para as inovações, que são cada vez mais interativas e colaborativas. Por exemplo, uma possível sinalização seria estabelecer taxas de juros menores para projetos que envolvessem mais de uma empresa ou mais de um ator do SNI. De forma geral, o crédito deveria complementar outros instrumentos que tenham impacto maior para redução de risco. Portanto, o uso de recursos reembolsáveis de forma isolada dificulta a capacidade do Estado de induzir e fomentar atividades de inovação. Além disso, pode acabar levando a projetos de menor impacto e relevância tecnológica.

Outros instrumentos do lado da oferta, que têm potencial maior de redução de risco, como a subvenção econômica ou o recurso não reembolsável para interação ICT-empresa, representaram menos de $5 \%$ na implementação da PIE. Esses são utilizados de maneira robusta nas políticas de países inovadores, como Alemanha, Finlândia, EUA e Suécia (CZARNITZKI et al., 2007; BLOCK, 2011). A subvenção econômica, devido às suas características intrínsecas, pode contribuir para mudanças nas estratégias das corporações, como destacado na seção 2. Dada a relevância desse instrumento, ele poderia ser utilizado para áreas ou temas estratégicos de governo a fim de fomentar projetos em que o poder público quisesse contribuir para a mudança nas trajetórias tecnológicas e rotinas das firmas. A não implementação da subvenção demonstra a dificuldade do Estado brasileiro de compreender a importância desse instrumento para estimular projetos de maior complexidade tecnológica. Muitas vezes, o governo tende a enxergar a subvenção com visão de curto prazo, como gasto para os cofres públicos, sem retorno imediato. No entanto, as empresas mais inovadoras tendem a ser aquelas com maior capacidade competitiva no longo prazo e, assim, tendem a ser aquelas que geram mais empregos, pagam mais impostos e sustentam um círculo virtuoso de desenvolvimento (MAZZUCATO, 2013; FREEMAN e SOETE, 2008). Assim, investimento em inovação pode gerar ganho maior para a economia no longo prazo. O fomento ou a indução nas empresas por atividades de maior valor agregado necessita de esforço do Estado no uso de instrumentos como o de subvenção. As firmas, nos seus processos inovativos, teriam estímulo maior para realizar atividades de maior complexidade tecnológica e para mudarem suas rotinas internas. Mesmo com a falha, dada a natureza de incerteza nas atividades de $\mathrm{P} \& \mathrm{D}$, pode-se produzir uma ação de aprendizado e geração de conhecimentos que contribuem para o aumento da competitividade.

Do ponto de vista dos instrumentos do lado da demanda, no PIE, o uso foi praticamente nulo. Compras públicas e encomendas tecnológicas são instrumentos de extrema importância em vários países para o estímulo a inovação, por exemplo, EUA 
e Suécia (ROLFSTAM, 2012; ROTHWELL, 1983; LEMBER et al., 2014; MAZZUCATO, 2013). No entanto, observa-se que o Estado brasileiro não os tem empregado como variável de estímulo à atividade de $\mathrm{P} \& \mathrm{D}$. O PIE poderia ter implementado os instrumentos do lado da demanda de forma mais robusta em algumas de suas áreas prioritárias, como saúde, defesa e petróleo e gás. Por exemplo, no caso do setor de saúde, o SUS é a principal demandante de produtos e serviços da área (GADELHA, 2012). Inovações na área da saúde têm um caráter de contribuir para o desenvolvimento social na medida em que podem ajudar a melhorar o acesso a diagnósticos de doenças e a áreas remotas, além de desenvolver endogenamente conhecimento. No caso de petróleo e gás, a maior empresa brasileira é a Petrobras. As encomendas e compras da estatal poderiam sinalizar para sua cadeia as tecnologias que pretende adquirir e, dessa forma, impulsionar as firmas a desenvolvê-las. Por exemplo, os projetos de inovação que forem mais competitivos teriam maior chance de serem adquiridos pela Petrobras. Dessa maneira, cria-se um portfólio para a companhia poder acessar e adquirir conforme suas necessidades, a exemplo do que faz o Defense Advanced Research Projects Agency (DARPA) na área de defesa nos EUA (BLOCK, 2011).

Outra característica da implementação do PIE foi o baixo estímulo à interação entre os diferentes atores do SNI, apesar de essa ser uma das premissas da política. Um exemplo é o baixo uso de recursos não reembolsáveis para impulsionar a interação entre empresa e ICT. A troca de conhecimento e o aprendizado gerado nessas relações podem contribuir para as corporações no processo de geração de novas oportunidades. A firma teria acesso a conhecimentos que, muitas vezes, internamente, não tem ou a equipe interna não visualizou. Uma ação estruturante a partir desse instrumento é buscar focar a parceria entre ICT e empresas a partir das demandas das firmas, como se verifica no caso da Alemanha na Fraunhofer. Nesse contexto, o desenvolvimento de conhecimento estaria ligado às necessidades das corporações e de sua competitividade, deixando de ser um desenvolvimento isolado das ICT e passando a ser de interesse do setor produtivo.

Outro fator importante para induzir e fomentar as interações sistêmicas se dá a partir de instrumentos de demanda pública. Nesse contexto, existe a possibilidade de estimular a troca de conhecimento entre diferentes atores, por exemplo, usando as encomendas públicas como impulso central para a interação entre diferentes agentes do SNI. Portanto, a partir dos instrumentos de demanda pública, poder-se-iam incentivar os desafios nacionais como fatores estruturantes de indução de desenvolvimento tecnológico, por exemplo, em mobilidade urbana, novas fontes de energia, saúde, cidades inteligentes, sustentabilidade, entre outros. Nesse contexto, poder-se-iam integrar variados instrumentos de forma que, a partir das demandas públicas, se alterassem as rotinas das empresas e se criassem mercados para essas. Outro fator que não se notou foi 
o incentivo à interação entre usuário e produtor, por exemplo, a subvenção poderia ser destinada a projetos com esse perfil (ROCHA, 2015). Assim, a falta de uma estratégia associada à indução das atividades cooperativas dificulta o fortalecimento do processo de aprendizado que, por pressuposto, é interativo.

Em estudo recente, Rocha (2015, p. 58) analisa os dados dos diferentes instrumentos de política de inovação e chega a conclusões semelhantes àquelas apontadas neste trabalho: "however, innovation policy in Brazil has very feebly been driven towards demand requirements. Linking demand to supply instruments seems to be the great challenge to be matched in next policy steps".

Portanto, de certa forma, pode-se dizer que políticas que não implementem instrumentos de redução de risco e incerteza tendem a não induzir e fomentar projetos de maior complexidade tecnológica capazes de gerar impactos sociais e fortalecer a competitividade da indústria nacional.

O estímulo ao investimento privado requer o uso de instrumentos e sinalização corretos de indução por parte do Estado. De modo geral, não é suficiente fomentar projetos de maior complexidade tecnológica ou alavancar investimentos privados sem a aplicação dos encorajamentos corretos para o setor produtivo. Assim, o uso de instrumentos que reduzem o risco e a incerteza do processo de inovação tende a ser um fator essencial para incentivar as empresas a investir mais em inovação. Economias líderes mundiais, como Alemanha e EUA, utilizam esses instrumentos como fatores de incentivo à inovação e, dessa maneira, impulsionam o setor privado a realizar investimentos em geração de novos conhecimentos para aumentar sua competitividade (MAZZUCATO, 2013; ROCHA, 2015; PEREIRA et al., 2015). Nesses países, o Estado tem o papel central de induzir os investimentos das firmas em inovação (FREEMAN e SOETE, 2008; PEREIRA e DATHEIN, 2016). Dessa maneira, a função do poder público não é meramente passiva e reguladora. $\mathrm{O}$ governo tem papel de induzir atividades de inovação, alterar incentivos, criar mercados e mudar rotinas (FREEMAN e SOETE, 2008; MAZZUCATO, 2013). Portanto, cabe ao poder público brasileiro uma atitude mais ativa de disponibilizar um conjunto variado de instrumentos em torno de uma estratégia de forma a aumentar a capacidade inovativa e os investimentos nessa área no país.

\section{CONCLUSÃO}

O trabalho procurou demonstrar que o Brasil foi capaz de planejar uma política de inovação para a qual foi disponibilizado um variado conjunto de instrumentos e prioridades estabelecidas. No entanto, a implementação da política acabou se 
restringindo a um modelo em que o papel do Estado não foi central para direcionar e induzir atividades de inovação de maior complexidade na economia nacional. Em grande medida, a política se restringiu à concessão de crédito para as empresas, o que, de fato, não representa nenhuma novidade em relação ao que já era feito no país.

Para o Brasil se tornar um país mais inovativo, é necessário que o Estado passe a utilizar instrumentos capazes de estimular e induzir as empresas a inovarem em projetos com maior agregação e difusão de conhecimento. Além disso, as ações precisam focar na troca de conhecimento entre os diferentes atores do SNI em torno de agendas nacionais. Para isso, o Estado precisa colocar nas suas prioridades o uso de instrumentos que reduzam riscos e incertezas, como subvenções econômicas, recursos não reembolsáveis para interação empresa e ICT e compras públicas. Esses deveriam se tornar, de certa forma, os pilares das políticas de inovação. Em grande medida, a dificuldade de estruturar instrumentos de demanda, capazes de alterar a rotina das empresas, é uma característica negativa do Estado brasileiro.

O governo deveria procurar estimular a atividade de inovação a partir de um mix de instrumentos cuja função deve ser de induzir, fomentar e criar mercados que possam levar as firmas a aumentar sua capacidade inovativa e seus investimentos em inovação. O governo poderia ter um conjunto de ações focadas a partir das demandas estratégicas do Estado e das empresas e, assim, estruturar as ações a partir de instrumentos de redução de risco e incerteza. Dessa maneira, o poder público tem a propriedade de mudar o processo de geração e difusão endógena de novos conhecimentos.

Uma possível área para desenvolvimento futuro nesse tema é fazer uma análise dos projetos em si no sentido de verificar a característica do que realmente foi apoiado. Esse tipo de análise poderia contribuir para se entender se projetos com variados instrumentos tiveram características distintas daqueles apoiados com um único instrumento, principalmente no tocante a complexidade e risco dos projetos.

\section{REFERÊNCIAS}

ARBIX, G.; DE NEGRI, J. A. “Avançar ou avançar na política de inovação”. In: DE TONI, J. (Org.). Dez anos de política industrial: balanços e perspectivas. Brasília: ABDI, 2015, p. 41-60.

ATKINSON, R. D.; EZELL, S. J. Innovation economics: the race for global advantage. New Haven: Yale University Press, 2012.

BLOCK, F. Where do innovations come from? Transformations in the U.S. economy - 19702006. Working Papers in Technology Governance and Economic Dynamics, The Other Canon Foundation, Norway; Tallinn University of Technology, Tallinn, n. 35, 2011. 
BNDES - BANCO NACIONAL DE DESENVOLVIMENTO ECONÔMICO E SOCIAL. Edital de seleção pública conjunta ANEEL BNDES/FINEP de apoio à inovação tecnológica no setor elétrico - Inova Energia - 01/2013. Rio de Janeiro: BNDES, 2013a. Disponível em: <http:// www.bndes.gov.br/SiteBNDES/export/sites/default/bndes_pt/Galerias/Arquivos/ produtos/download/inova_energia_edital.pdf>. Acesso em: 10 mar. 2018.

BNDES - BANCO NACIONAL DE DESENVOLVIMENTO ECONÔMICO E SOCIAL. Edital de seleção pública conjunta BNDES/Finep/MCTI/Ministério da Sáude de apoio à inovação tecnológica no setor de equipamentos médicos e tecnologias para a saúde - Inova Saúde equipamentos médicos - 02/2013. Rio de Janeiro: BNDES, 2013b. Disponível em: <http:// www.bndespar.gov.br/SiteBNDES/export/sites/default/bndes_pt/Galerias/Arquivos/ produtos/download/Inova_Saude_Edital.pdf>. Acesso em: 10 mar. 2018.

BRASIL. MCT - MINISTÉRIO DE CIÊNCIA E TECNOLOGIA. Plano Inova Empresa. Brasília, DF: MCT, 2013. Disponível em: <http://www.mct.gov.br/upd_blob/0225/225828.pdf>. Acesso em: 10 mar. 2018.

CORDER, S.; BUAINAIN, A. M.; JUNIOR, I. D. S. L. Análise preliminar do plano inova empresa. Blucher Engineering Proceedings, v. 3, n. 4, p. 156-173, 2016.

CONNELL, D. Creating markets for things that don't exist - The truth about UK government $\mathrm{R} \& \mathrm{D}$ and how the success of SBRI points the way to a new innovation policy to help bridge the Valley of Death and rebalance the UK economy. Cambridge: Centre for Business Research, 2014.

COSTA, A. C.; SZAPIRO, M.; CASSIOLATO, J. E. Análise da operação do instrumento de subvenção econômica à inovação no Brasil. In: CONFERÊNCIA INTERNACIONAL LALICS 2013, Rio de Janeiro, 2013.

CUNNINGHAN, P. N.; GOK, A. Impact of innovation policy schemes for collaboration, compendium of evidence on the effectiveness of innovation policy intervention. London/ Manchester: NESTA/MIOIR, 2012.

CZARNITZKI, D.; EBERSBERGER, B.; FIERI, A. The relationship between R\&D collaboration, subsidies and R\&D performance: Empirical evidence from Finland and Germany. Journal of Applied Econometrics, v. 22, p. 1347-1366, 2007.

DODGSON, M. "As políticas para ciência, tecnologia e inovação nas economias asiáticas de industrialização recente”. In: KIM, L.; NELSON, R. R. (Org.). Tecnologia, aprendizados e inovação - As experiências das economias de industrialização recente. Campinas: Editora Unicamp, 2005, p. 313-364.

EDLER, J. Demand-based innovation policy. Manchester: Manchester Business School, 2007.

EDLER, J. et al. Impacts of innovation policy: synthesis and conclusions. Nesta Working Paper, 2013.

FERRAZ, J. F.; MARQUES, F. S.; ALVES JR., A. J. “A contribuição do BNDES para a política industrial brasileira/2003-2014”. In: DE TONI, J. (Org.). Dez anos de política industrial: balanços e perspectivas. Brasília: ABDI, 2015, p. 61-92.

FINEP - FINANCIADORA DE ESTUDOS E PROJETOS. Edital de seleção pública conjunta FINEP/BNDES/MD/AEB de apoio à inovação tecnológica nos setores aeroespacial, defesa e segurança - Inova Aerodefesa - 04/2013. FINEP, 2013a Disponível em: <http://www.finep. gov.br/chamadas-publicas/chamadapublica/574>. Acesso em: 10 mar. 2018. 
FINEP - FINANCIADORA DE ESTUDOS E PROJETOS. Edital de seleção pública conjunta FINEP/MCTI/MS/CNPQ de apoio à inovação tecnológica no setor de saúde - Inova Saúde biofármacos, farmoquímicos e medicamentos - 03/2013. FINEP, 2013b. Disponível em: $<$ http://www.finep.gov.br/chamadas-publicas/chamadapublica/551>. Acesso em: 10 mar. 2018.

FREEMAN, C. Technology policy and economic performance. Londres: Pinter Publishers, 1989.

FREEMAN, C.; SOETE, A. Economia da inovação industrial. Campinas: Editora Unicamp, 2008.

GADELHA, C. A. G. "Política industrial, desenvolvimento e os grandes desafios nacionais”. In: LASTRES, H. M. M. et al. (Orgs.). O futuro do desenvolvimento: ensaios em homenagem a Luciano Coutinho. Campinas: Editora Unicamp, 2016, p. 215-251.

GADELHA, C. A. G.; COSTA, L. S.; MALDONADO, J. O complexo econômico-industrial da saúde e a dimensão social e econômica do desenvolvimento. Revista de Sáude Pública, n. 46, p. 21-28, 2012.

GRAMKOW, C.; GORDON, J. L. P. L. Aspectos estruturais da economia brasileira: heterogeneidade estrutural e inserção externa de 1996 a 2009. Cadernos do Desenvolvimento, v. 9, n. 15, p. 35-61, 2015.

GORDON, J. L. P. L. Papel do estado na política de inovação brasileira 2007-2015: uma análise do uso dos principais instrumentos. Tese (Doutorado em Economia da Indústria e da Tecnologia) - Instituto de Economia, Universidade Federal do Rio de Janeiro, Rio de Janeiro, 2017.

KOELLER, P. Política nacional de inovação no Brasil: releitura das estratégias do período 19952006. 2009. Tese (Doutorado em Economia da Indústria e da Tecnologia) - Instituto de Economia da Universidade Federal do Rio de Janeiro, Rio de Janeiro, 2009.

LAZONICK, W. The Innovative Enterprise and the Developmental State: Toward an Economics of Organizational Success. Institute for New Economic Thinking. In: ANNUAL 2011 CONFERENCE CRISIS AND RENEWAL: INTERNATIONAL POLITICAL ECONOMY AT THE CROSSROADS - AIRnet Working Paper. EUA, Abril, 2011.

LEMBER, V.; KATTEL, R.; KALVET, T. Public procurement and innovation: theory and practice. Public procurement, innovation and policy. Berlim: Editora Springer-Verlag, 2014.

LUNDVALL, B-Å. Innovation system research: where it came from and where it might go. Globelics Working Paper, Saratov, Global Network for Economics of Learning, Innovation, and Competence Building System, No 2007-01, 2007.

MAZZUCATO, M. The Entrepreneurial State: debunking public vs. private myths in risk and innovation. London: Anthem Press, 2013.

MAZZUCATO, M.; PENNA, C. C. R. The Brazilian innovation system: a mission oriented policy proposal. Brasília: CGEE, 2016.

MELO, L. M.; CARVALHO, M. B. da S. O financiamento da inovação e indicadores de inovação: Finep 30 dias. In: SEMINÁRIO DE PESQUISA DO IE-UFRJ, Rio de Janeiro, 2013.

MENDONÇA, H. L.; VAN ADUARD DE MACEDO-SOARES, T. D. L.; FONSECA, M. V. d. A. Working towards a framework based on mission-oriented practices for assessing renewable energy innovation policies. Journal of Cleaner Production, v. 193, p. 709-719, 2018. 
MOWERY, D. C. “Military and innovation”. In: HALL, H.; ROSENBERG, N. Handbook of the Economics Innovation. v. 2. Amsterdam: Elsevier, 2010, p. 1221-1256.

PERREIRA, A. J.; DATHEIN, R. Política industrial como instituição desenvolvimentista: uma crítica ao "novo desenvolvimentismo" baseada nas experiências de Brasil e Coreia do Sul. Revista de Economia Contemporânea, v. 20, n. 1, p. 28-57, 2016.

PERREIRA, F. dos S.; BOMTEMPO, J. V.; ALVES, F.C. Programa de subvenção às atividades de PD\&I: uma comparação em biocombustível no Brasil, EUA e Europa. Revista Brasileira de Inovação. v. 14, n. especial, 2015.

ROCHA, F. Does governmental support to innovation have positive effect on R\&D investments? Evidence from Brazil. Revista Brasileira de Inovação, v. 14, n. especial, p. 37-60, 2015.

ROLFSTAM, M. Public procurement of innovation: demand as in command or facilitation of endogenous knowledge conversion? Prepared for the conference on Demand, Innovation and Policy: Underpinning Policy Trends with Academic Analysis. Manchester Institute of Innovation Research, MBS, University of Manchester, Manchester, UK, 22-23 March, 2012.

ROTHWELL, R. "The difficulties of national innovation policies". In: MACDONALD, S.; LAMBERTON, D.; MANDEVILLE, T. The trouble with technology: explorations in the process of technological change. Londres: Frances Pinter, 1983.

ROTHWELL, R.; ZEGVELD, W. (Eds). Industrial innovation and public policy. Londres: Pinter Publishers, 1981.

ZUCOLOTO, G. F. Lei do Bem: impactos nas atividades de P\&D no Brasil. Radar - Tecnologia, Produção e Comércio Exterior, n. 6, p. 14-20, 2010. 